\title{
Needle biopsy size and pathological Gleason Score diagnosis: No evidence for a link
}

\author{
Antonio Cicione, MD; ${ }^{*}$ Francesco Cantiello, MD, ${ }^{*}$ Cosimo De Nunzio, MD; ${ }^{\dagger}$ Andrea Tubaro, PhD, MD; ${ }^{+}$ \\ Rocco Damiano, PhD, $M D^{*}$
}

*Urology Unit, Magna Graecia University of Catanzaro, Catanzaro, Italy; ‘La Sapienza University, Department of Urology, Sant’ Andrea Hospital, Rome, Italy

Cite as: Can Urol Assoc J 2013;7(9-10):e567-71. http://dx.doi.org/10.5489/cuai.311 Published online September 10, 2013.

\section{Abstract}

Background: Biopsy Gleason score (GS), in combination with other clinical parameters, is important to take a therapeutic decision for patients with diagnosis of localized prostate cancer. However, preoperative GS is often upgraded after a radical prostatectomy. Increasing the amount of tissue in prostate biopsy may be a way to avoid this issue. We evaluate the influence of a larger biopsy needle size on the concordance between biopsy and pathological GS.

Methods: We analyzed paired biopsies and prostatectomy specimens from 104 cases of men with clinically localized prostate cancer. At the time of prostate biopsy, the patients were prospectively randomized into two needle groups (16-Gauge [G] and 18G) using a 1:1 ratio. GS concordance was estimated performing kappa statistic testing, overall concordance rate and risk to under grade biopsy $\mathrm{GS}=6$. A logistic regression analysis was performed to evaluate the patients' characteristics as possible risk factors.

Results: The overall concordance between prostate biopsy and pathological GS was $76.9 \%$ and $75.6 \%(p=0.875)$ and the $\mathrm{k}$ values were 0.821 and $0.811(p=0.424)$, respectively, for $16 \mathrm{G}$ and $18 \mathrm{G}$ needle study groups. The risk to undergrade a biopsy $\mathrm{GS}=6$ was $21.1 \%$ and $15.4 \%(p=0.709)$ using a $16 \mathrm{G}$ and $18 \mathrm{G}$ needle, respectively. Age, prostate-specific antigen, prostate volume and needle calibre were not independently associated with a higher risk of GS discordance.

Conclusions: Needle size does not affect the concordance between biopsy and pathological GS. Although GS is not the only way to determine treatment, it is still an unresolved urological issue.

\section{Introduction}

Gleason score (GS) on needle biopsy is one of the most important parameters in planning treatment for clinically localized prostate cancer. It is also included in many nomograms to assess cancer recurrence risk after active treat- ment. Accurate assessment is essential, but a discordance risk between biopsy and pathological GS may occur. In general, needle biopsy underestimates pathological Gleason grade in $30 \%$ of cases and overestimates it in $5 \%$ to $10 \%$ of cases. ${ }^{1}$

Although a 16-gauge (16G) needle may also be used to perform prostate biopsy, studies ${ }^{1-4}$ on GS concordance are based on 18G needles in combination with a biopsy gun, transrectal ultrasound guidance and the 12-core prostate biopsy template. ${ }^{2,3}$ McCormack and colleagues have recently showed that the 16G needle for prostate biopsy is safe, but does not increase prostate cancer detection rate. ${ }^{5}$ Until now the 16G needle GS concordance grade has not yet been assessed.

The aim of this study is to investigate the GS concordance between diagnostic prostate biopsy and a radical prostatectomy specimen using a $16 \mathrm{G}$ or $18 \mathrm{G}$ needle to perform a transrectal extended (12 cores) prostate biopsy.

\section{Methods}

The study flow diagram is shown in Fig. 1. From September 2009 to December 2011, we gathered patients who were referred to our tertiary care institution with a prostate-specific antigen (PSA) level $\geq 4 \mathrm{ng} / \mathrm{mL}$ and/or a suspected digital rectal examination (DRE); they were scheduled for transrectal ultrasound guided prostate biopsy (TRUS). Through a computer-generated schedule, these patients were prospectively randomized with 1:1 ratio into 2 groups: Group 1 is the $16 \mathrm{G}$ group, where a $16 \mathrm{G}$-calibre needle was used to take samples during TRUS and Group 2, where a 18G-calibre needle was used. Then, the diagnosed prostate cancer cases with radical prostatectomy were analyzed for GS concordance (that is, having the same GS on diagnostic biopsy and surgical specimen). The degree of concordance was assessed by calculating, for each needle group, a kappa statistic, overall concordance rate and the risk to undergrade a biopsy GS=6. The clinical and pathological GS were separated in two group: $\mathrm{GS}=6$ and $\mathrm{GS} \geq 7$. The overall biopsy 
GS was based on the core with the highest GS, while in radical prostatectomy specimens with multifocal disease, it was based on the nodule with the highest GS.

All patients received oral quinolone antibiotic (500 mg ciprofloxacin twice daily) the day before TRUS and this was continued for 4 days after biopsy. Moreover, each patient was instructed to perform a pre-biopsy rectal enema. A single operator (AC) performed the extended (12 cores) TRUS using a periprostatic block analgesia ${ }^{6}$ and a single pathologist was responsible for histological diagnosis and to allocate GS in biopsy and surgical specimens.

At the end of TRUS, each biopsy sampling was evaluated for the presence of fragmentation and short length core (less than $10 \mathrm{~mm}$ ); a modified Clavien classification system was adopted to assess biopsy complications. ${ }^{7}$

Prostate volume was determined by transrectal prostate ultrasound through the ellipse formula and a $7.5-\mathrm{MHz}$ endorectal end-fire probe.

Radical retropubic prostatectomy was performed within 8 weeks after prostate biopsy using the technique described by Walsh and colleagues ${ }^{8}$ and prostate cancer stage was assigned according to the 2010 TNM. ${ }^{9}$
If patients had a previous prostate biopsy, active anorectal disease, allergy to local anesthetic, androgen deprivation therapy or radiotherapy before the radical prostatectomy, they were excluded from the study analysis. The protocol was approved by our Institutional Review Board and informed consent was obtained by each participant.

\section{Statistical analysis}

The data were normally distributed. The Student's t-test and chi-square test were used for ordinal and categorical variables, respectively. A bivariate and multivariate logistic regression was developed to determine whether age, total PSA, PSA ratio, prostate volume and needle calibre were important predictors of GS concordance. A $p$ value $<0.05$ was considered statistically significant. All data were analyzed using Statistical Package for Social Science (SPSS) 18.0 for Windows.

\section{Results}

There were 140 patients in each group (Fig. 1). Of these, 104 patients with localized prostate cancer and who had under-

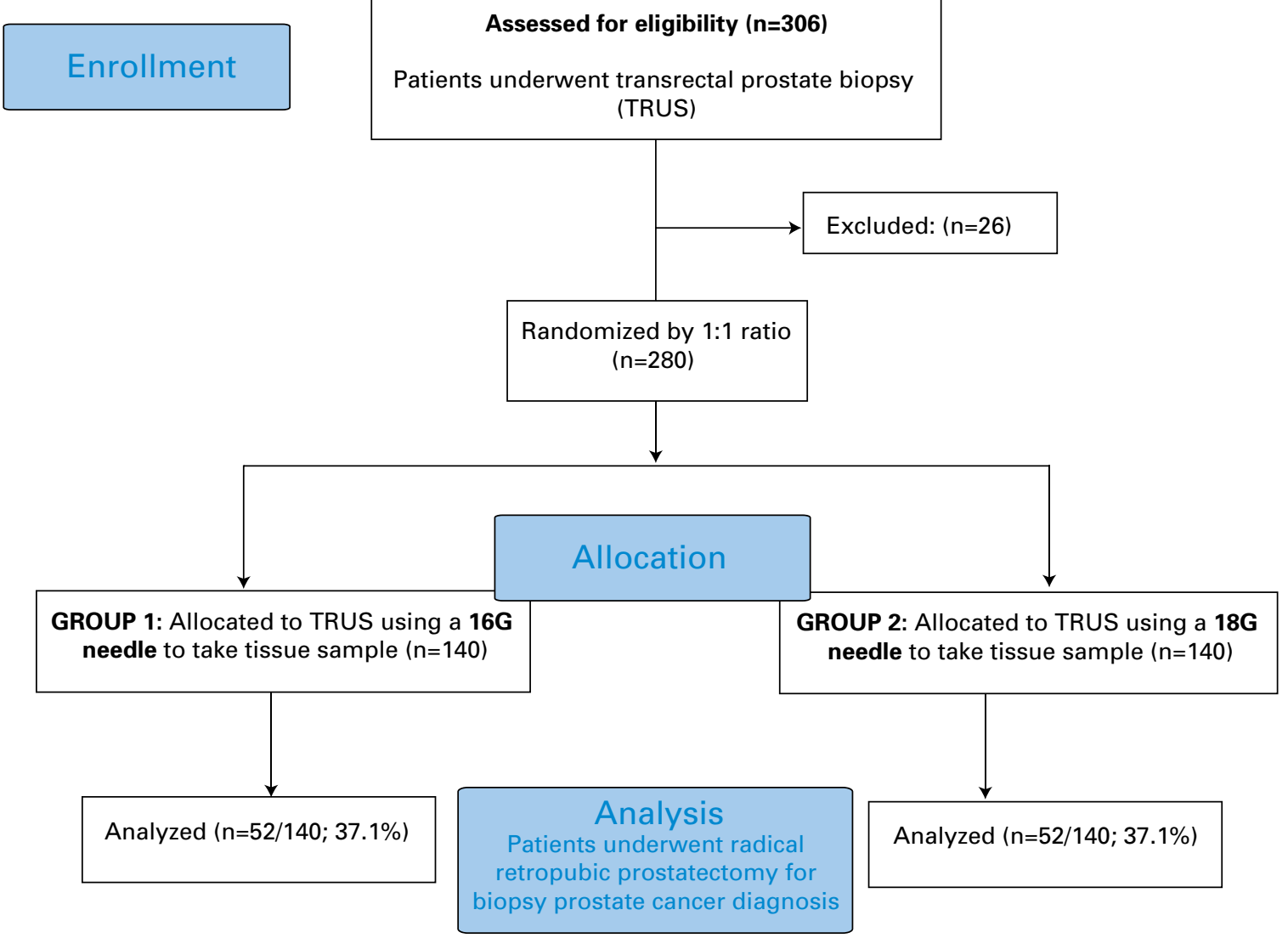

Fig. 1. Study flow diagram. 
gone a radical retropubic prostatectomy were analyzed for GS concordance. In total, there were 52 patients in Group $1(37.1 \%)$ with a diagnosis of prostate cancer compared to 54 in Group $2(38.5 \%)(p=0.762)$. We excluded the last 2 patients from Group 2 (the 18G group) so that both groups were equal in number for comparison.

We tallied patient characteristics (Table 1). There were no significant differences for age and prostate volume between the two groups. The median PSA at diagnosis was 7.8 and $6.86 \mathrm{ng} / \mathrm{mL}$, in Group 1 and 2, respectively. The median PSA ratio was $14.6 \%$ and $15.9 \%$, in Group 1 and 2, respectively.

In each study group, most prostate cancers were GS=6 at prostate biopsy: $40(76.9 \%)$ patients in Group 1 and $38(73.1 \%)$ patients in Group 2. Subsequently, pathological GS $=6$ and GS $\geq 7$ were revealed in $29(55.7 \%)$ and 23 $(44.3 \%)$ patients and in $30(57.6 \%)$ and $22(42.4 \%)$ patients, in Groups 1 and 2, respectively.

The main pathological prostate cancer stage was organ confined (pT2 in 32 and 35 patients) and all the biopsy samplings had cores longer than $10 \mathrm{~mm}$ without fragmentation.

Moreover, the use of a $16 \mathrm{G}$ needle appeared to be safe (Table 2$) ; 10$ patients $(7.3 \%)$ and $6(4.2 \%)$, respectively, had Grade 1 and Grade 2 complications compared to 9 (6.3\%) and $4(3 \%)$ patients in the $18 \mathrm{G}$ group.

We tallied the concordance between biopsy and pathological Gleason scores for each group (Table 3). The K coefficient was 0.821 and $0.811(p=0.424)$, the overall GS concordance rate was $76.9 \%$ and $75.6 \%(p=0.875)$, the risk to undergrade a biopsy GS=6 was $21.1 \%$ and $15.4 \%$ $(p=0.709)$ using 16G or 18G needle biopsy, respectively. Using the multivariate logistic regression analysis (Table 4), none of the variables evaluated in our study was independently associated with a higher risk of discordance between biopsy and pathological GS.

\section{Discussion}

The Gleason grading system is one of the most important means to predict and choose treatment for men with prostate cancer. GS is indispensable to predict pathological stage, lymph node or distant metastasis. ${ }^{10}$ Moreover, in the era of non-invasive treatment options for prostate cancer, such as radiotherapy or active surveillance, where the only tissue sampled is on prostate biopsy, it is important that the grade obtained from the biopsy accurately reflects that of the tumour in the prostate after radical prostatectomy.

However, a risk of discrepancy between biopsy and surgical GS is decrypted and many reasons can cause it, such as sampling error, inter- and intra-observer variability and the pathologist's experience. ${ }^{11}$

Inal and colleagues ${ }^{12}$ reported a better histological quality sampling using a $16 \mathrm{G}$ needle to perform transrectal prostate biopsy and McCormack and colleagues ${ }^{5}$ recently

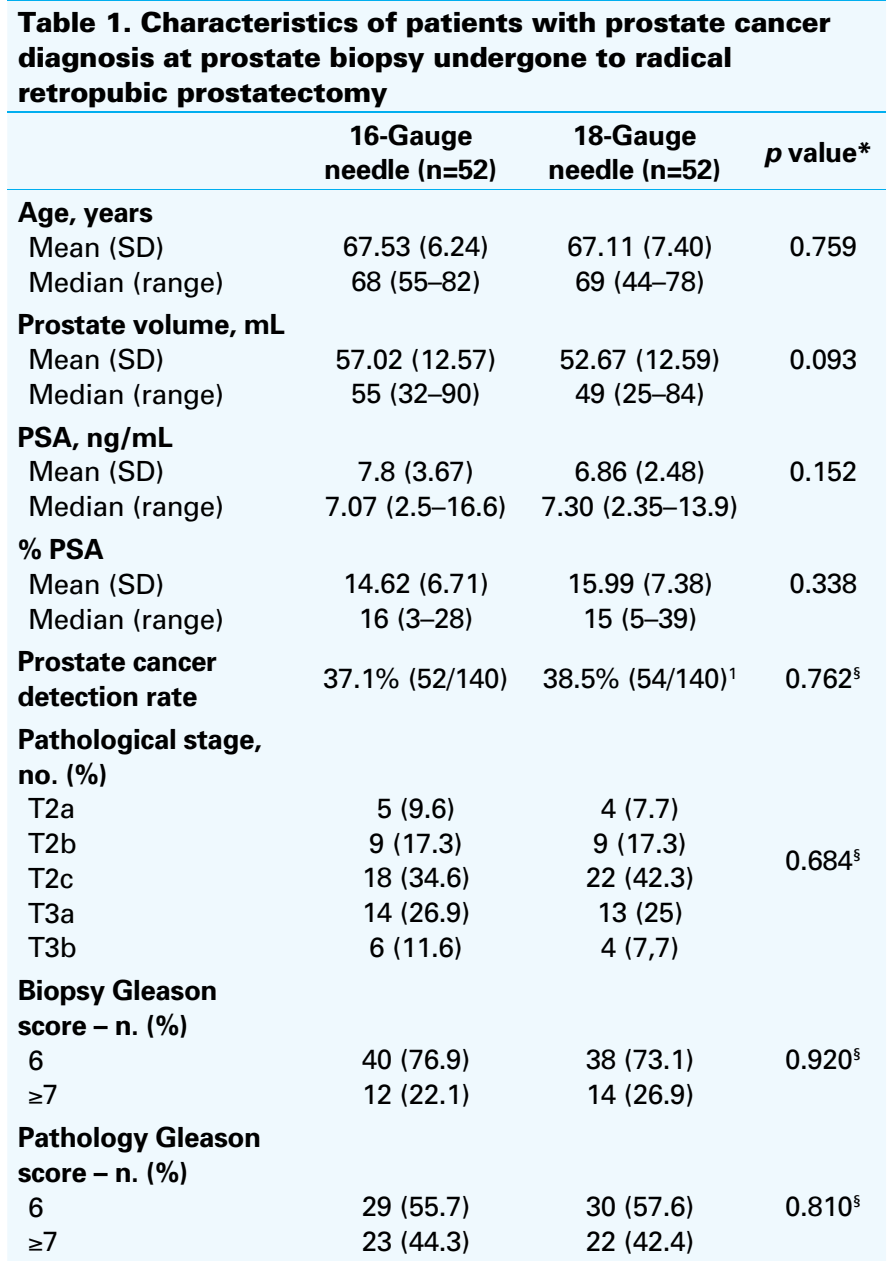

SD: standard deviation; PSA: prostate-specific antigen. ${ }^{*}$ t-Student test; §chi-square test; 'The last two patients were excluded from analysis to have an equal number to compare.

showed that the $16 \mathrm{G}$ needle does not increase prostate cancer detection.

The goal of this study was to evaluate whether using a larger needle, 16G, to perform a prostate biopsy might increase the concordance between clinical and pathological GS. A 16G needle is about 1.5 times wider than a 18G needed, therefore it is reasonable to speculate that using a $16 \mathrm{G}$ can increase the quantity and quality of tissue specimen and, ultimately, improve GS concordance.

However, we found no statistical difference between 16G and 18G in GS concordance. Each needle displayed a high overall concordance rate and fine $k$ coefficient. The $k$ statistic is a measure of agreement between two observations and its values range from -1 to +1 . $K$ values greater than 0.75 represent excellent agreement. ${ }^{13}$ Moreover, these findings concurred with previous studies with $18 \mathrm{G}$ needles and an extended biopsy scheme $\mathrm{e}^{1,3}$ and in transperineal biopsy approach. $^{2}$

A discordant GS may be due to a sampling error; this does not mean that the needles were not large enough, but rather 


\begin{tabular}{|c|c|c|c|c|}
\hline & & $\begin{array}{c}\text { 16-Gauge } \\
\text { needle } \\
(n=140)\end{array}$ & $\begin{array}{c}\text { 18-Gauge } \\
\text { needle } \\
(n=140)\end{array}$ & $p$ value* \\
\hline Grade 0 & $\begin{array}{c}\text { Normal post-biopsy } \\
\text { course }\end{array}$ & $\begin{array}{c}124 \\
(88.5 \%)\end{array}$ & $\begin{array}{c}127 \\
(90.7 \%)\end{array}$ & 0.823 \\
\hline Grade 1 & $\begin{array}{l}\text { Complications } \\
\text { with need of } \\
\text { medication (fewer } \\
\text { or rectal bleeding } \\
\text { manageable by } \\
\text { compression) }\end{array}$ & $10(7.3 \%)$ & $9(6.3 \%)$ & 0.981 \\
\hline Grade 2 & $\begin{array}{l}\text { Complications with } \\
\text { need to surgical } \\
\text { treatment (bleeding } \\
\text { manageable only } \\
\text { by endoscopic } \\
\text { treatment) }\end{array}$ & $6(4.2 \%)$ & $4(3 \%)$ & 0.634 \\
\hline
\end{tabular}

the needles (whatever gauge) are not sampling the relevant dominant tumour nodules or the higher grade component. ${ }^{14}$ In fact, Rubin and colleagues showed that the GS correlation rate is worse $(52.4 \%)$ if prostate cancer is diagnosed in less than $1 \mathrm{~mm}$ or $5 \%$ of one biopsy core and only one Gleason pattern is recognizable. ${ }^{14}$ Therefore, it is reasonable that the needle may be the only tool to work with when taking tissue and its calibre does not improve prostate cancer detection and the GS correlation. An image-guided tool to get at tumour-concentrated tissue may be a solution for the GS discrepancy issue.

Although undergrading biopsy GS is the most common problem, ${ }^{11}$ overgrading biopsy GS may also occur; we did not evaluate this issue for 2 reasons. The first reason is that we did not consider biopsy GS less than 6 because it is generally considered the cutoff for low-dying risk from prostate cancer $^{15,16}$ and because Gleason pattern one and two are usually rare and seen in the transition zone, so it is unlikely to find a biopsy GS less than 6 . Moreover referring GS $\leq 4$ in a biopsy report is not indicated. ${ }^{17}$ The second reason is that, although intermediate- and high-GS risk classes are described, ${ }^{18}$ we included them in only one because deferred treatment ${ }^{18}$ or brachytherapy ${ }^{19,20}$ for prostate cancer is not indicated in cases of biopsy $\mathrm{GS} \geq 7$. Moreover the World Health Organization consensus conference suggests reporting the worst GS pattern, even if it is not the predominant or secondary pattern. ${ }^{11,17}$

No statistical difference was found in sample quality between $16 \mathrm{G}$ or $18 \mathrm{G}$ needles; this was not the aim of the study, but we needed to assess this to avoid bias. Fragmentation and short core may impede the possibility of correctly assessing the GS in the prostate biopsy sample. ${ }^{11,17,21}$

Our results seem to support McCormack's findings, ${ }^{5}$ which suggest safety and prostate cancer detection using the $16 \mathrm{G}$ or $18 \mathrm{G}$ needle.

\begin{tabular}{|c|c|c|c|}
\hline & $\begin{array}{l}\text { 16-Gauge } \\
\text { needle }\end{array}$ & $\begin{array}{c}\text { 18-Gauge } \\
\text { needle }\end{array}$ & $p$ value ${ }^{*}$ \\
\hline$K$ coefficient & 0.821 & 0.811 & 0.424 \\
\hline $\begin{array}{l}\text { Overall concordance } \\
\text { (biopsy GS confirmed at RRP) }\end{array}$ & 41 (78.9) & $44(84.6)$ & 0.875 \\
\hline $\begin{array}{l}\text { Under-grade risk } \\
\text { (pathological GS } \geq 7 \text { detected as } \\
\text { GS }=6 \text { at biopsy) }\end{array}$ & $11(21.1)$ & $8(15.4)$ & 0.709 \\
\hline
\end{tabular}

Table 4. Results of multivariate logistic regression model to predict Gleason score upgrading

\begin{tabular}{lcc}
\hline & OR $(95 \%$ Cl) & $\boldsymbol{p}$ value* \\
\hline Age & $0.906(0.827-0.992)$ & 0.303 \\
Prostate volume & $0.997(0.954-1.041)$ & 0.880 \\
PSA level & $1.22(1.007-1.477)$ & 0.42 \\
PSA ratio & $0.967(0.896-1.043)$ & 0.387 \\
Needle calibre & $1.055(0.384-2.901)$ & 0.917 \\
\hline GS: Gleason score; PSA: prostate-specific antigen; OR: odds ratio; Cl: confidence interval.
\end{tabular}

Finally, multivariate analysis did not show a correlation between GS concordance and age, prostate volume, PSA total and free serum level, regardless of the type of needle used. Smaller prostate volume was suggested by Sfoungaristos and colleagues ${ }^{22}$ as a predictor for upgrading GS, but in our cohort the mean prostate volume size was 57 and $52 \mathrm{~cm}^{3}$ for the both needle groups.

We must acknowledge some important study limitations. We did not evaluate the prostate cancer volume, its position and percent of core tumour involvement. Therefore, we cannot establish if more tissue samples may reduce the sampling error. In particular, the heterogeneous and multifocal nature of prostate cancer may lead to an under- or overgrading error according to where and how much tissue is sampled by the needle. ${ }^{23}$ Although our sample number is acceptable for a pilot study, it could be small to assess minute differences in the use of 16G or 18G needle for TRUS.

To date, our prospective study is the first to compare 16G and 18G needles in GS concordance using a standard extended biopsy scheme (and obtaining a quality sample) in patients undergoing their first prostate biopsy. A single biopsy operator and single pathologist, evaluating sample quality and using a 12-core biopsy have improved the strength of this study. Intra- and inter-observed errors were avoided and the use of an extended scheme increased the correlation rate. ${ }^{2,3}$

Finally, we found that the Gleason concordance is not influenced by needle calibre. The risk of undergrading biopsy $\mathrm{GS}=6$ must be considered when a therapeutic option for prostate cancer is chosen. However, the use of other findings (such as patient age, PSA level and comorbidity) in deciding treatment and management, makes the decision a more careful one. 


\section{Conclusions}

In our experience, biopsy needle size does not influence the concordance between biopsy and pathological GS; the undergrade biopsy $\mathrm{GS}=6$ was the most frequent discordance error. Therefore, in the era of extended biopsy protocol and less invasive treatment for prostate cancer, urologists should be aware that GS upgrading after biopsy is still an unresolved issue. Further studies and technologies should be developed to minimize this possible bias associated with important implications for prostate cancer treatment.

Competing interests: None declared.

This paper has been peer-reviewed.

Acknowledgments: The authors acknowledge Kimberlee Manzi from the University "La Tuscia," Viterbo, Italy, who provided English editing support.

\section{References}

1. Thickman D, Speers WC, Philpott PJ, et al. Effect of the number of core biopsies of the prostate on predicting Gleason score of prostate cancer. J Urol 1996;156:110-3. http://dx.doi.org/10.1016/ S0022-5347(01)65956-1

2. Emiliozzi P, Maymone S, Paterno A, et al Increased accuracy of biopsy Gleason score obtained by extended needle biopsy. J Urol 2004;172:2224-6. http://dx.doi.org/10.1097/01.ju.0000144456.67352.63

3. San Francisco IF, DeWolf WC, Rosen S, et al. Extended prostate needle biopsy improves concordance of Gleason grading between prostate needle biopsy and radical prostatectomy. I Urol 2003;169:136-40. http://dx.doi.org/10.1016/S0022-5347(05)64053-0

4. Cookson MS, Fleshner NE, Soloway SM, et al. Correlation between Gleason score of needle biopsy and radical prostatectomy specimen: accuracy and clinical implications. J Urol 1997;157:559-62. hittp:// dx.doi.org/10.1016/S0022-5347(01)65201-7

5. McCormack M, Duclos A, Latour $M$, et al. Effect of needle size on cancer detection, pain, bleeding and infection in TRUS-guided prostate biopsies: A prospective trial. Can Urol Assoc J 2012;6:97-101. http:// dx.doi.org/10.5489/cuaj.11169

6. Trucchi A, De Nunzio C, Mariani S, et al. Local anesthesia reduces pain associated with transrectal prostatic biopsy. A prospective randomized study. Urol Int 2005;74:209-13. http://dx.doi. org/10.1159/000083550

7. Dindo D, Demartines N, Clavien PA. Classification of surgical complications: a new proposal with evaluation in a cohort of 6,336 patients and results of a survey. Ann Surg 2004;240:205-13. http://dx.doi. org/10.1097/01.sla.0000133083.54934.ae
8. Walsh PC, Retik AB, Vaughan ED Jr, et al. Anatomic radical retropubic prostatectomy. In: Campbell's Urology. 8th ed, vol. 4. Philadelphia: Saunders; 2002:3107-29.

9. Edge SB, Byrd DR, Compton CC, et al. Prostate. In: AJCC Cancer Staging Manual. 7th ed. New York: Springer;2010:457-68.

10. Partin AW, Kattan MW, Subong EN, et al. Combination of prostate-specific antigen, clinical stage, and Gleason score to predict pathological stage of localized prostate cancer. A multi-institutional update. JAMA 1997;277:1445-51. Erratum in: JAMA 1997;278:118. http://dx.doi.org/10.1001/ jama.1997.03540420041027

11. Montironi R, Mazzuccheli R, Scarpelli M, et al. Gleason grading of prostate cancer in needle biopsies or radical prostatectomy specimens: contemporary approach, current clinical significance and sources of pathology discrepancies. BJU Int 2005;98:1146-52. http://dx.doi.org/10.1111/.1.1464-410X.2005.05540.x

12. Inal $\mathrm{GH}$, Oztekin $\mathrm{VC}, \mathrm{U}$ urlu 0 , et al. Sixteen gauge needles improve specimen quality but not cancer detection rate in transrectal ultrasound-guided 10-core prostate biopsies. Prostate Cancer Prostatic Dis 2008;11:270-3. http://dx.doi.org/10.1038/pcan.2008.34

13. Fleiss JL. The measure of interrater agreement. In: Statistical methods for Rates and Proportions. 2nd ed. John Wiley \& Sons, New York; 1981:212-36.

14. Rubin MA, Dunn R, Kambham N, et al. Should a Gleason score be assigned to a minute focus of carcinoma on prostate biopsy? Am J Surg Pathol 2000;24:1634-40. http://dx.doi.org/10.1097/00000478200012000-00007

15. Scattoni V, Zlotta A, Montironi R, et al. Extended and saturation prostatic biopsy in the diagnosis and characterisation of prostate cancer: a critical analysis of the literature. Eur Urol 2007;52:1309-22. http:// dx.doi.org/10.1016/j.eururo.2007.08.006

16. Albertsen PC, Hanley JA, Gleason DF, et al. Competing risk analysis of men aged 55 to 74 years at diagnosis managed conservatively for clinically localized prostate cancer. JAMA 1998;280:975-80. http://dx.doi.org/10.1001/jama.280.11.975

17. Epstein Jl. An update of the Gleason grading system. J Urol 2010;183:433-40. http://dx.doi. org/10.1016/i.juro.2009.10.046

18. Heidenreich A, Bolla M, Joniau $S$, et al. EAU Guidelines on prostate Cancer. Paper presented at the EAU Annual Congress, Vienna 2011:33-42.

19. D'Amico AV, Whittington R, Malkowicz SB, et al. Biochemical outcome after radical prostatectomy, external beam radiation therapy, or interstitial radiation therapy for clinically localized prostate cancer. JAMA 1998;280:969-74. http://dx.doi.org/10.1001/jama.280.11.969

20. Kattan MW, Potters L, Blasko JC, et al. Pretreatment nomogram for predicting freedom from recurrence after permanent prostate brachytherapy in prostate cancer. Urology 2001;58:393-9. http://dx.doi. org/10.1016/50090-4295(01)01233-X

21. Fajardo DA, Epstein Jl. Fragmentation of prostatic needle biopsy cores containing adenocarcinoma: the role of specimen submission. BJU Int 2010;105:172-5. http://dx.doi.org/10.1111/j.1464410X.2009.08737.x

22. Sfoungaristos $S$, Perimenis $P$. Clinical and pathological variables that predict changes in tumour grade after radical prostatectomy in patients with prostate cancer. Can Urol Assoc J 2013;7:E93-7. hittp:// dx.doi.org/10.5489/cuaj.270

23. Corcoran NM, Hovens $C M$, Hong MK, et al. Underestimation of Gleason score at prostate biopsy reflects sampling error in lower volume tumours. BJU Int 2012;109:660-4. http://dx.doi.org/10.1111/j.1464410X.2011.10543.x. Epub 2011 Sep 2.

Correspondence: Dr. Antonio Cicione, Urology Unit, Magna Graecia University of Catanzaro, Viale Europa, Germaneto, Catanzaro 88100, Italy; fax: 039-09613647184; acicione@libero.it 